\title{
Antarctic summer sea ice concentration and extent: comparison of ODEN 2006 ship observations, satellite passive microwave and NIC sea ice charts
}

\author{
B. Ozsoy-Cicek ${ }^{1}$, H. Xie ${ }^{1}$, S. F. Ackley ${ }^{1}$, and K. Ye ${ }^{2}$ \\ ${ }^{1}$ Laboratory for Remote Sensing and Geoinformatics, Department of Geological Sciences, University of Texas at San \\ Antonio, Texas 78249, USA \\ ${ }^{2}$ Department of Management Science and Statistics, University of Texas at San Antonio, Texas, USA
}

Received: 17 June 2008 - Published in The Cryosphere Discuss.: 22 July 2008

Revised: 2 December 2008 - Accepted: 24 December 2008 - Published: 3 February 2009

\begin{abstract}
Antarctic sea ice cover has shown a slight increase $(<1 \% /$ decade $)$ in overall observed ice extent as derived from satellite mapping from 1979 to 2008, contrary to the decline observed in the Arctic regions. Spatial and temporal variations of the Antarctic sea ice however remain a significant problem to monitor and understand, primarily due to the vastness and remoteness of the region. While satellite remote sensing has provided and has great future potential to monitor the variations and changes of sea ice, uncertainties remain unresolved. In this study, the National Ice Center (NIC) ice edge and the AMSR-E (Advanced Microwave Scanning Radiometer-Earth Observing System) ice extent are examined, while the ASPeCt (Antarctic Sea Ice Process and Climate) ship observations from the Oden expedition in December 2006 are used as ground truth to verify the two products during Antarctic summer. While there is a general linear trend between ASPeCt and AMSR-E ice concentration estimates, there is poor correlation $\left(R^{2}=0.41\right)$ and AMSR-E tends to underestimate the low ice concentrations. We also found that the NIC sea ice edge agrees well with ship observations, while the AMSR-E shows the ice edge further south, consistent with its poorer detection of low ice concentrations. The northward extent of the ice edge at the time of observation (NIC) had mean values varying from $38 \mathrm{~km}$ to $102 \mathrm{~km}$ greater on different days for the area as compared with the AMSR-E sea ice extent. For the circumpolar area as a whole in the December period examined, AMSR-E therefore may underestimate the area inside the ice edge at this time by up to $14 \%$ or, 1.5 million $\mathrm{km}^{2}$ less area, compared to the NIC ice charts. Preliminary comparison of satellite
\end{abstract}

\section{Correspondence to: B. Ozsoy-Cicek} (Burcu@drcicek.com) scatterometer data however, suggests better resolution of low concentrations than passive microwave, and therefore better agreement with ship observations and NIC charts of the area inside the ice edge during Antarctic summer. A reanalysis data set for Antarctic sea ice extent that relies on the decade long scatterometer and high resolution satellite data set, instead of passive microwave, may therefore give better fidelity for the recent sea ice climatology.

\section{Introduction}

Sea ice in both hemispheres is expected to respond sensitively to climate change. Sea ice insulates and influences the heat transfer, mass, exchange of gases and interaction between the atmosphere and ocean. The Antarctic pack ice is a region of highly variable ice responding to winds, air temperatures and ocean currents. Ice motion causes floes to collide and deform while at the same time creating areas of open water between floes, quantified as either the open water or ice concentration fraction. In winter, cold air temperatures drive new ice growth at the highest growth rates in the open water areas, while in summer, these areas of open water of low albedo absorb solar radiation and warm up, enhancing the ice melt (Hunke and Ackley, 1998; Nihashi and Cavalieri, 2006; Nihashi and Ohshima, 2001).

It is difficult to examine Antarctic sea ice time-varying characteristics due to the vastness and remoteness of the region. Satellite remote sensing data, in principle, allow detection of changes in ice concentration and ice extent (the northern-most position of the ice edge at a given time) over large areas. Passive microwave sensors, unhampered by cloud cover and darkness are particularly well suited to

Published by Copernicus Publications on behalf of the European Geosciences Union. 
obtain a large spatial and long temporal record of sea ice concentration and extent (Comiso and Nishio, 2008). However, ice characteristics from space have shown weaker correlation with ship-based observations in summer than in winter, both for ice concentration (Knuth and Ackley, 2006) and ice extent (Worby and Comiso, 2004). These summer studies showed differences between ship observations and satellite passive microwave (SSM/I) of, typically, $\pm 20 \%$ in ice concentration and up to 1-2 degrees latitude $(>100 \mathrm{~km})$ in ice extent. While the discrepancies in ice concentration tend to average out over large numbers of measurements (Knuth and Ackley, 2006), the bias in ice extent is one-sided, where ship observations found ice edges further north than observed by satellite microwave (Worby and Comiso, 2004). For the presatellite era (prior to 1960s), de la Mare (1997) used whale catch data as a proxy for summer ice edge location. He inferred that the post 1960 s sea ice area had reduced by $25 \%$ compared to the earlier period from this analysis. Ackley et al. (2003) suggested instead that the one-sided extent bias between ship observations and satellite data could account for a significant portion of this difference. However, there were very limited crossings of the sea ice edge by ships, in comparison with satellite observations, to examine this inference fully.

Understanding the regional changes of Antarctic sea ice and its response to global climate change is crucial, however, and increasing the accuracy of satellite estimates is therefore necessary for the long term monitoring of sea ice and for comparison to model predictions. In this study, we have used the new (since 2002) AMSR-E's (The Advanced Microwave Scanning Radiometer-Earth Observing System) geophysical product for ice concentration, to see if it better correlates with summer sea ice conditions at the surface than the SSM/I data of previous comparisons. We compare these microwave estimates of ice concentration and ice edge determination to ice observations made aboard ship in the Antarctic pack ice during the Swedish icebreaker Oden 2006 expedition. Ice edge location comparison has also been made between the two data sets, ship ice observations and National Ice Center (NIC) daily charts. NIC ice chart analyses rely more heavily on high resolution satellite imagery such as active radar and visible imagery when visibility (clouds) allows. We then obtain a quantitative and areally extensive estimate of the differences in summer ice extent between the two remotely obtained products, AMSR-E and NIC ice charts, over the larger West Antarctic sea ice zone.

\section{Data}

\subsection{Ship observations}

Observational data on sea ice morphology and distribution was systematically collected as the Polar Icebreaker Oden transited through the Bellingshausen, Amundsen and Ross seas in Antarctic summer season (December 2006). The data collected included ice concentration, ice type, ice thickness, floe size, topography, and snow cover (snow type and thickness). Meteorological data, including sea temperature, air temperature, wind speed, direction, cloud cover and visibility, were recorded and summarized.

Ice observations were made according to the ASPeCt protocols (Worby and Allison, 1999; www.aspect.aq) that provide a standardized and quantifiable method for observing sea ice that is now accepted as the international standard. Estimates of ice concentration, ice type with its thickness, floe size, and snow type with its depths were made. Observations were made every half an hour ( $\sim 11 \mathrm{~km}$ distance separation) from the Oden's bridge within a radius of approximately $1 \mathrm{~km}$ from the ship. The generated ship track for summer ice observations from 13 to 26 December 2006 is shown in Fig. 1. Observations started on 19 December 2006, when the vessel first entered the sea ice region (Fig. 1) and were made between $67^{\circ} 53 \mathrm{~S} / 102^{\circ} 97 \mathrm{~W}$ and $73^{\circ} 52 \mathrm{~S} / 178^{\circ} 54 \mathrm{E}$. The frequency and number of observations increased on 22 December when a more highly concentrated sea ice area was encountered and were made continuously through the pack ice zone of the Ross Sea from 23 to 25 December. Ice observations from Oden every half an hour were entered on log sheets using a standard set of codes based on the WMO (1970) nomenclature and designed exclusively for Antarctic sea ice (Worby and Allison, 1999). We have used the ASPeCt software to enter a series of classification codes for each ice parameter. After the cruise, the ASPeCt data was checked for quality control against digital time-lapse video recordings provided by the Oden operations team taken from the bridge window of the ship every ten minutes. We recorded a total of $171 \mathrm{ASPeCt}$ observations including four full days (22, 23, 24, 25 December), the 19 December (11 observations), and the 21 December (1 observation). From the 171 ice observations made, the average ice concentration derived was $44 \%$, ice thickness was $107.8 \mathrm{~cm}$, and snow thickness was $30 \mathrm{~cm}$ before entering the Ross Sea Polynya $\left(73^{\circ} 52 \mathrm{~S}, 178^{\circ} 54 \mathrm{E}\right)$.

\subsection{Satellite data}

The AMSR-E instrument provides passive microwave data expressed as horizontally and vertically polarized brightness temperature $(\mathrm{Tb})$ from $6.9,10.7,18.7,23.8,36.5$, and $89(\mathrm{GHz})$ frequencies. The spatial resolution of the data (pixel size) is $12.5 \mathrm{~km}$ by $12.5 \mathrm{~km}$. AMSR-E microwave remote sensing uses various algorithms to estimate the snow depth, sea ice concentration (NASA Team 2), and snowice interface temperature (Cavalieri et al., 1997; Comiso et al., 2003; Markus and Cavalieri, 2000). The AMSRE's geophysical products of ice concentration (Cavalieri and Comiso, 2004) are updated daily (AMSR-E/Aqua Daily L3 $12.5 \mathrm{~km} \mathrm{~Tb}$, Sea Ice Conc. and Snow Depth Polar Grids) and were obtained from the National Snow and Ice Data Center 


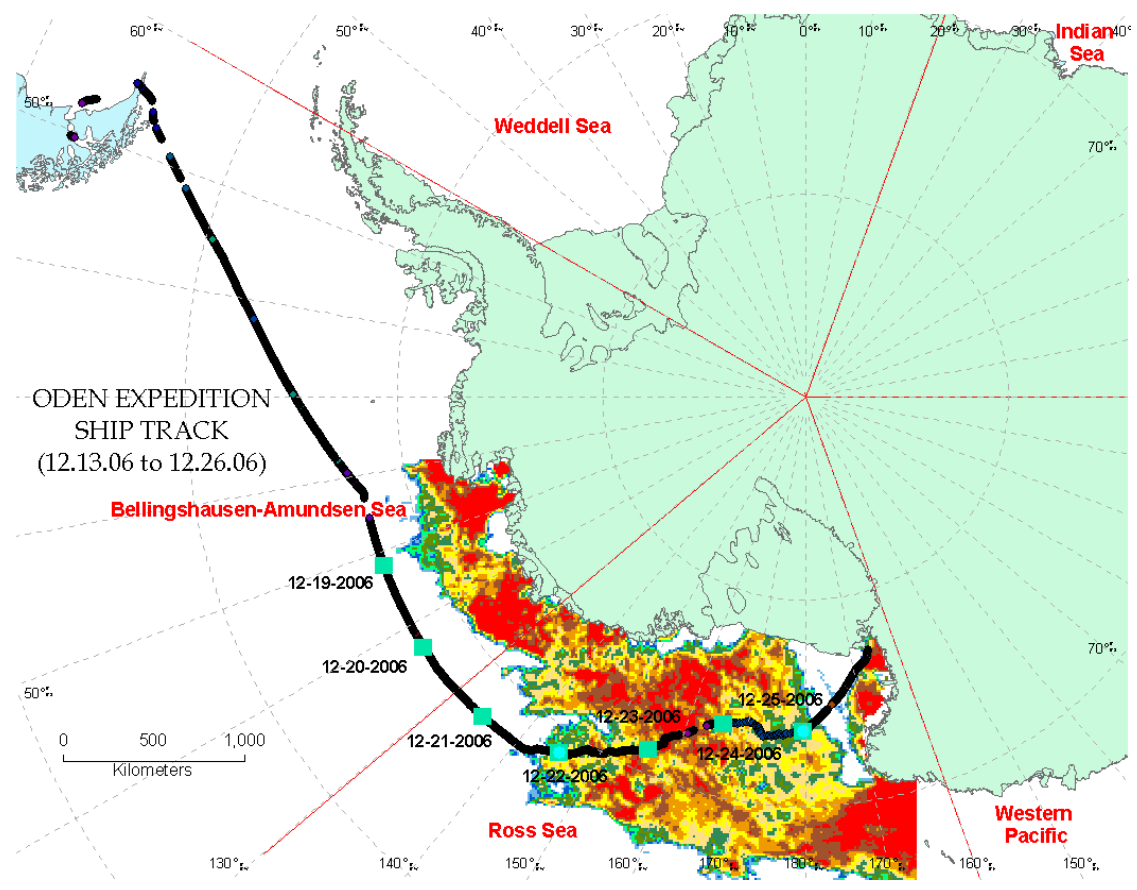

Fig. 1. Map showing the Oden Antarctic Cruise track for this study - December 2006. The thin red lines show the boundaries of the sectors (Ross Sea, Western Pacific, Indian Ocean, Weddell Sea, and Bellingshausen-Amundsen Sea) that are used to characterize regionally the sea ice areas of the Antarctic. The region with colors indicates the sea ice concentration determined from AMSR-E for 23 December 2006. Color code of the estimated ice concentrations is the same as in Fig. 5.

(www.NSIDC.org). The region of study for the comparison includes the West Antarctic sea ice zone which is particularly interesting since the sea ice of the area has shown significant changes in the satellite era (Cavalieri and Parkinson, 2008). Systematic decreases in ice extent in the BellingshausenAmundsen Seas sector have been balanced by increases in the Ross Sea sector (Parkinson, 2002; Comiso and Nishio, 2008).

\subsection{National Ice Center ice edge data}

The third data set is the daily ice edge products obtained from the National Ice Center (NIC, www.natice.noaa.gov) for the same period of 22-25 December 2006. NIC originally produced its ice charts using all available satellite imagery, in-situ reports and meteorological/oceanographic guidance data. The sources of these data are (1) shore station reports, (2) ship reports, (3) aerial reconnaissance, (4) buoy reports, (5) meteorological guidance products, (6) ice prediction model output, (7) climatology and sea ice information obtained from international partners such as foreign ice services, and (8) satellite imagery (Godin, 1981). The last group, satellite imagery, however, dominated (prior to 1981 and since). Satellites provide between 90 and $98 \%$ of the data. NIC charts provide consistent integration of the various satellite sources as well as quality control of the final products by a trained ice observer. NIC chart inputs to the data can range in resolution from $200 \mathrm{~m}$ to $25 \mathrm{~km}$. These inputs include RADARSAT, QuickSCAT, DMSP OLS (Defense Meteorological Satellite Program Operational Linescan System), AVHRR (Advanced Very High Resolution Radiometer), and SSM/I (Special Sensor Microwave Imager). The SSM/I contour also uses the NASA Team 2 algorithm. NIC prefers to use the Scatterometer/QuikSCAT images over passive microwave data. Basically, NIC ice analysts bring the SSM/I contour into the Sea Ice Mapping System (SIMS) as a shapefile (GIS compatible) and modify the contour using available imagery (QuickSCAT, Visible/IR, or RADARSAT) by visual analysis. NIC data uses satellite passive microwave information which is derived from a sensor different than AMSR-E, and is highly adjusted by using higher resolution data. Based on a large number of charts produced, the average percentages of various types of imagery used in producing the charts is found at (www.natice. noaa.gov) and listed as: Supplemental Information: SSM/I (1.87\%), AVHRR (16.73\%), ENVISAT (5.43\%), QuikSCAT (36.67\%), MODIS (12.84\%), OLS (13.72\%), Remaining (12.74\% from e.g. climatology, drifting buoys, ship reports, etc.). Note that AMSR-E is not listed as used but the roughly equivalent passive microwave product SSM/I was used with however, a component of $<2 \%$ in contribution to the average production of an ice chart. NIC sea ice edge contours for the 4 days, as displayed in a GIS platform, are shown in Fig. 2. 


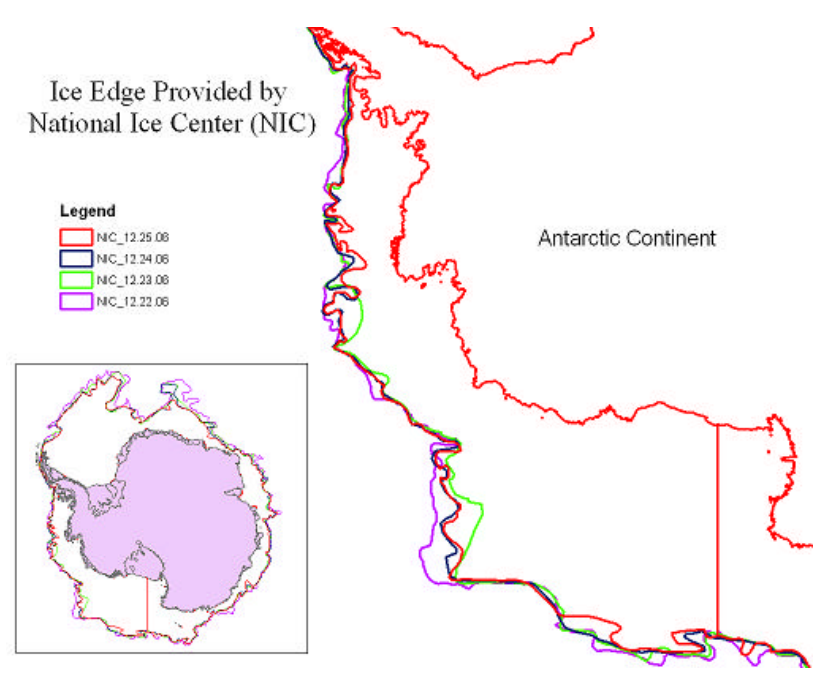

Fig. 2. National Ice Center Sea Ice Edge distributions for 22, 23, 24, and 25 December 2006.

Table 1. Statistics for the full dataset (\%).

\begin{tabular}{lccccc}
\hline Variable & $\mathrm{N}$ & $\begin{array}{c}\text { Mean } \\
\text { Conc. }\end{array}$ & $\begin{array}{c}\text { Std. } \\
\text { Dev }\end{array}$ & Minimum & Maximum \\
\hline AMSR-E & 171 & 56.7 & 31.2 & 0.0 & 98.4 \\
ASPeCt & 171 & 44.2 & 26.8 & 5.2 & 94.4 \\
\hline
\end{tabular}

\section{Results and analysis}

\subsection{Comparison of sea ice concentration between ASPeCt} and AMSR-E data

We generated a corresponding number for the sea ice concentration between each individual ASPeCt observation (total 171) and each AMSR-E measurement $(12.5 \times 12.5 \mathrm{~km})$ for the same location and day. Figure 3 shows the comparison between the two data sets and Table 1 includes the basic statistics of the two datasets. The comparison shows a general linear trend but with poor correlation $\left(R^{2}=0.41\right)$. We then introduced some averaging into the analysis of both data sets. Average sea ice concentration of the ASPeCt was calculated for every 10 pixels and compared with the averaged concentration computed from all the crossed AMSR-E pixels (Fig. 4). Even though the correlation is better $\left(R^{2}=0.85\right.$ for a linear relation), however, the AMSR-E underestimates the low concentrations and, for the most part, overestimates the high concentration, as shown by the data distribution relative to the 1:1 line in Fig. 3. Of particular interest is the region observed as less than $15 \%$ ice concentration from AMSR-E. The data indicate that concentrations observed from the vessel up to $50 \%$ are instead found.

As shown in Table 1, averages of ice concentration over the whole area are $\sim 12 \%$ higher from the satellite estimates

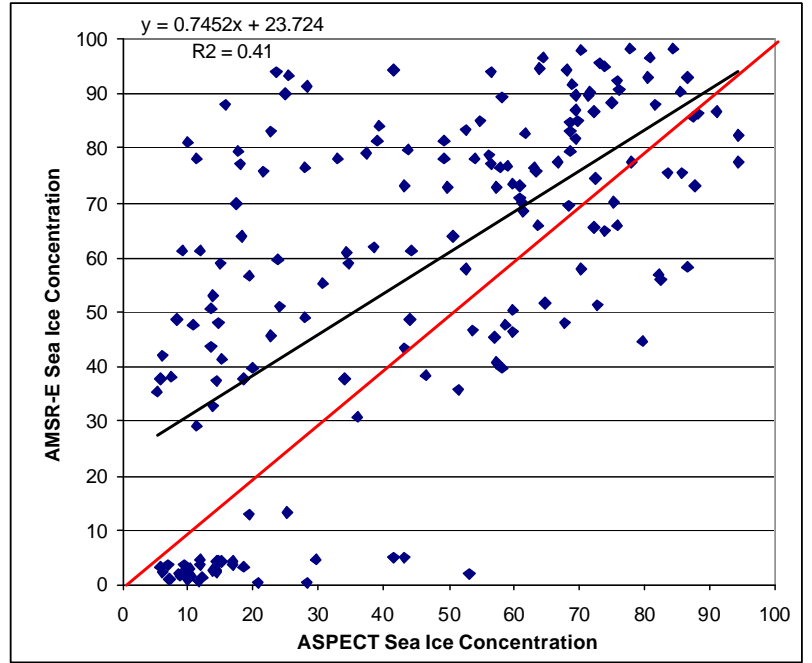

Fig. 3. Sea Ice Concentrations from observed ASPeCt data vs. from AMSR-E data. The solid black line represents best linear fit of the data while the solid red line represents the 1:1 line.

Table 2. Basic statistics of distance $(\mathrm{km})$ difference from NIC ice edge to AMSR-E ice edge: total area of study. A positive value indicates that the NIC ice edge is north of the AMSR-E ice edge.

\begin{tabular}{lccccc}
\hline Date & $\begin{array}{c}\text { Max. } \\
\text { Distance } \\
(\mathrm{km})\end{array}$ & $\begin{array}{c}\text { Min. } \\
\text { Distance } \\
(\mathrm{km})\end{array}$ & Mode & $\begin{array}{c}\text { Std. } \\
\text { Dev }\end{array}$ & Mean \\
\hline 22.12 .06 & 385.18 & -25.79 & 20.64 & 77.39 & 98.51 \\
23.12 .06 & 270.00 & -163.89 & 16.58 & 69.34 & 42.57 \\
24.12 .06 & 354.62 & -15.07 & 92.16 & 65.19 & 85.23 \\
25.12 .06 & 349.81 & -101.77 & 12.02 & 64.91 & 55.87 \\
\hline
\end{tabular}

compared to the ship estimates. While still a large difference, some of the variations shown in Fig. 3 have diminished by averaging (Fig. 4) since for any single ship estimate, the range of satellite estimates varied by $50 \%$ or greater.

\subsection{Comparison of sea ice edge between NIC, ASPeCt, and AMSR-E data}

Figure 5 shows the NIC and AMSR-E ice edge for the four days period, with the associated ASPeCt observations overlaid. While the NIC sea ice edge agrees well with ship observations for 22 December as shown in the upper left panel on Fig. 5, however, the passive microwave satellite data show the ice edge much further away on this date and generally for all other days. This comparison indicates that this passive microwave instrument (AMSR-E) has similar difficulty in detecting the exact summer ice edge as seen in a previous ship-to-satellite comparison (Worby and Comiso, 2004) using ice observations to compare with SSM/I data. 


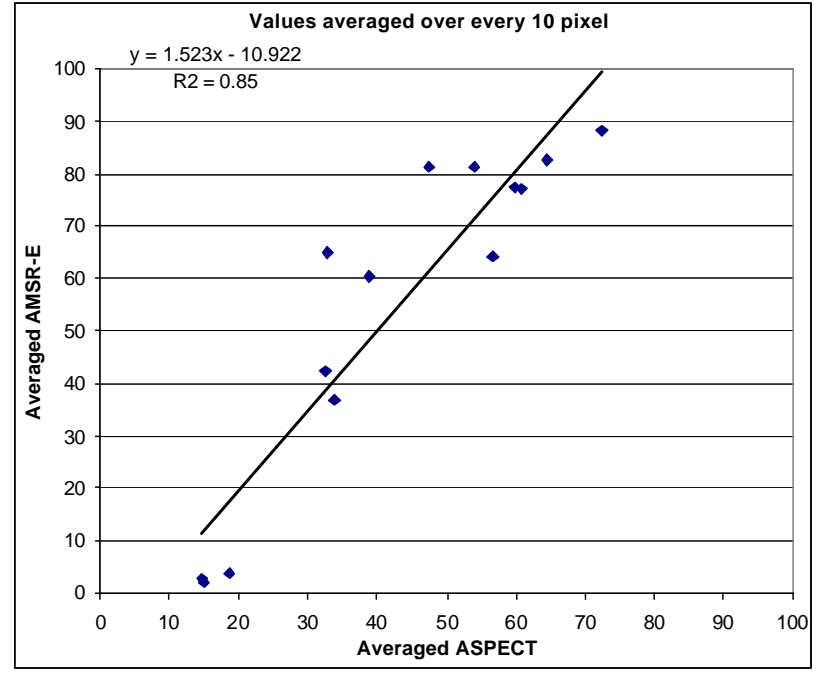

Fig. 4. Average sea ice concentrations of the ASPeCt and AMSR-E calculated for every 10 pixels.

To quantify the difference in ice edge position found between the AMSR-E and NIC ice chart, perpendicular lines were drawn at $50 \mathrm{~km}$ intervals along the NIC ice edge to the AMSR-E ice edge defined by the ice concentration. Nearly perpendicular lines were drawn along the ice edge to measure the distance between NIC and AMSR-E. Since the ice edge for both the NIC ice edge and the AMSR-E edge are "random (and uncorrelated) wavy lines", it is difficult to choose between representations that measures the distance in a consistent way between the two ice edges. We therefore chose to use parallel lines in a constant horizontal orientation on the image between the two rather than say, a due south orientation at all locations. Both methods are equally arbitrary, since it is easy to find locations where they would give either greater or less distance than the other method, suggesting these differences would average out to a similar value when taken over many measurements and would give similar max and min values also. By using a large number of parallel lines however of equal small separation, a total area between the two can be easily calculated by summing the trapezoidal areas formed by the two parallel lines and the separation distance (constant at $50 \mathrm{~km}$ ) along the respective ice edges of those parallel lines. This method is also easier to implement on the GIS platform used for the analysis than a constant direction vector. Table 2 shows the Max and Min distances, Mode (most frequently observed distance), Mean, and Standard Deviation for the entire region (Fig. 5). Tables 3 and 4 show no particular differences when the data are broken into two sectors (Bellingshausen-Amundsen Sea and Ross Sea) for this analysis. While there is a range of several hundred kms and some cases (negative Min distances) where the AMSR-E estimated edge was north of the NIC ice edge because of the measurement geometry, the mean
Table 3. Basic statistics of distance $(\mathrm{km})$ difference from NIC ice edge to AMSR-E ice edge: Bellingshausen-Amundsen Sea sector. A positive value indicates that the NIC ice edge is north of the AMSR-E ice edge.

\begin{tabular}{lcccc}
\hline Date & $\begin{array}{c}\text { Max. } \\
\text { Distance }(\mathrm{km})\end{array}$ & $\begin{array}{c}\text { Min. } \\
\text { Distance }(\mathrm{km})\end{array}$ & $\begin{array}{c}\text { Std. } \\
\text { Dev }\end{array}$ & Mean \\
\hline 22.12 .06 & 223.51 & 2.76 & 65.60 & 102.39 \\
23.12 .06 & 192.16 & -110.74 & 62.54 & 38.79 \\
24.12 .06 & 234.16 & 4.32 & 59.11 & 84.01 \\
25.12 .06 & 214.39 & -28.55 & 56.99 & 61.34 \\
\hline
\end{tabular}

Table 4. Basic statistics of distance $(\mathrm{km})$ difference from NIC ice edge to AMSR-E ice edge: Ross Sea sector. A positive value indicates that the NIC ice edge is north of the AMSR-E ice edge.

\begin{tabular}{lcccc}
\hline Date & $\begin{array}{c}\text { Max. } \\
\text { Distance } \\
(\mathrm{km})\end{array}$ & $\begin{array}{c}\text { Min. } \\
\text { Distance } \\
(\mathrm{km})\end{array}$ & $\begin{array}{c}\text { Std. } \\
\text { Dev }\end{array}$ & Mean \\
\hline 22.12 .06 & 385.18 & 0.20 & 80.51 & 96.72 \\
23.12 .06 & 270.00 & -163.89 & 73.31 & 44.72 \\
24.12 .06 & 354.62 & -15.07 & 69.10 & 85.98 \\
25.12 .06 & 349.81 & -101.77 & 69.04 & 52.88 \\
\hline
\end{tabular}

distance generally shows the effect of large regions of probably lower concentration that are missed by the AMSR-E but measured by the NIC charts (as confirmed by the Oden comparison shown in Fig. 5). The Mode values vary over a large range but only indicate that there are large sections of ice edge with similar offset on a given day. The mean values vary between $40 \mathrm{~km}$ and over $100 \mathrm{~km}$ positive, suggesting a significant underestimate of the mean summer extent by passive microwave, since the NIC ice charts appear to correspond better with available ship observations. Table 5 shows the areal difference for Antarctica when using the NIC chart as the ice edge as opposed to the AMSR-E. These differences show about a 7 to $14 \%$ underestimate of the sea ice area bounded by the ice edge determined by passive microwave (AMSR-E) compared to the NIC charts.

\subsection{Comparison of sea ice edge between QuikSCAT and AMSR-E data}

NASA's Quick Scatterometer, QuikSCAT, can detect sea ice using a different mechanism, the backscatter from an active radar signal, the scatterometer (Nghiem et al., 2005). With the current highest usage of scatterometer data to produce ice charts (36.7\% from above discussion) for the recent NIC ice charts; we wished to compare using scatterometer data alone to the passive microwave. At present, however, the scatterometer data is only available in analog (jpeg) form in an easily accessible way (Polarview website) to us. We therefore cannot digitally analyze them and can only make a 


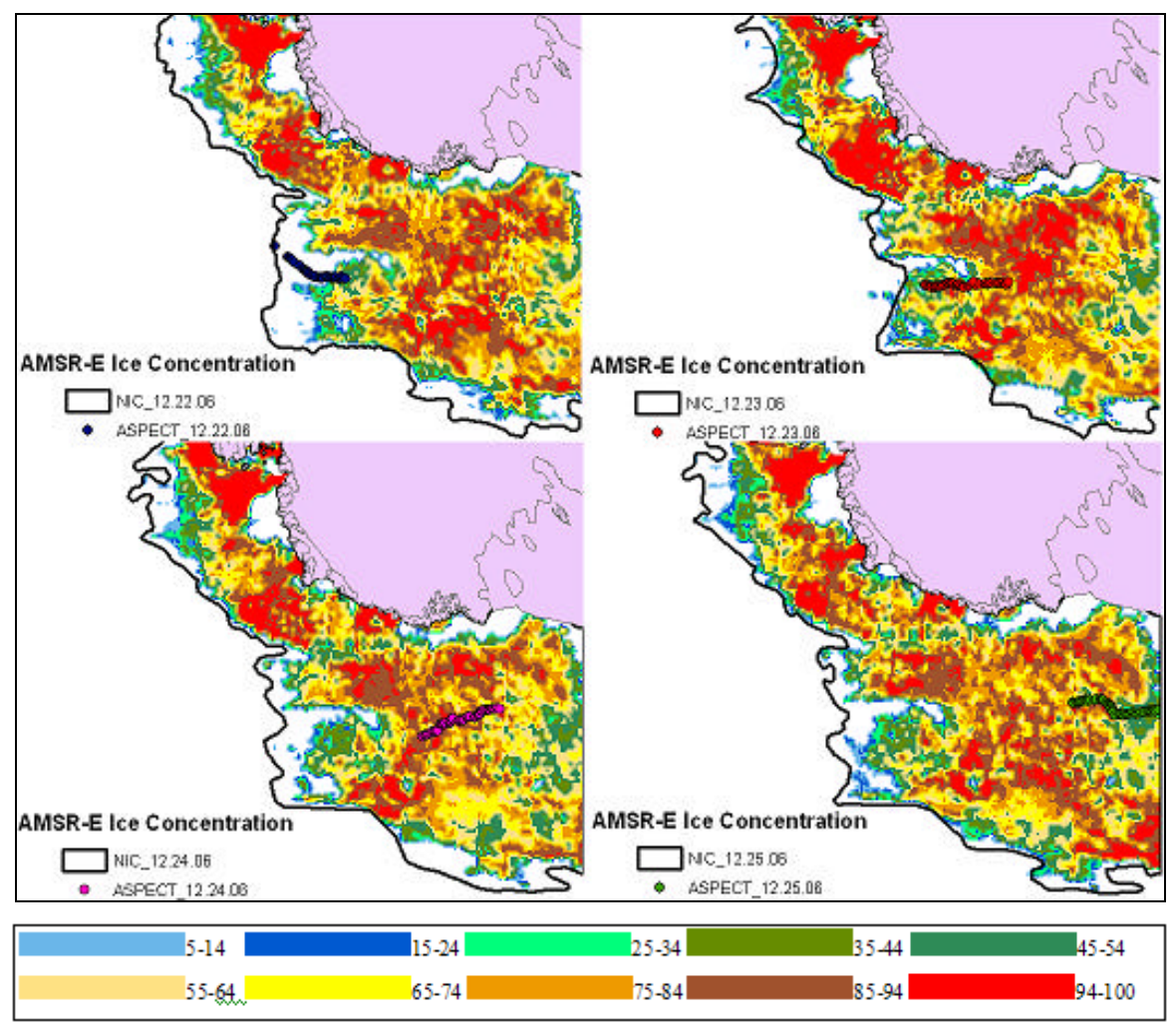

Fig. 5. Sea Ice Edge Comparison between the two data sets, NIC ice charts and AMSR-E ice concentration, for the 4 days. The outer limit of the colored area is defined as the ice edge on AMSR-E, i.e. the furthest northward pixel that contains ice. The dots show the positions of ASPeCt ship-based ice observations on the same day. Legend shows the AMSR-E sea ice concentrations derived using the NASA Team 2 algorithm.

Table 5. Sea ice covered area for each day and areal difference of Antarctic sea ice cover from AMSR-E and NIC.

\begin{tabular}{cccccc}
\hline Date & Mean & Pixel & $\begin{array}{c}\text { Total sea ice coverage } \\
\text { from AMSR-E }\left(\mathrm{km}^{2}\right)\end{array}$ & $\begin{array}{c}\text { NIC-AMSR-E } \\
\text { difference }\left(\mathrm{km}^{2}\right)\end{array}$ & $\begin{array}{c}\text { Total sea ice coverage } \\
\text { from NIC }\left(\mathrm{km}^{2}\right)\end{array}$ \\
\hline 22.12 & 70.15 & 18391 & 2873593. & 417954 & 3291547. \\
23.12 & 69.74 & 18250 & 2851562. & 193934 & 3045496. \\
24.12 & 68.12 & 18035 & 2817968. & 318436 & 3136404. \\
25.12 & 69.49 & 18153 & 2836406. & 233647 & 3070053. \\
\hline
\end{tabular}

general agreement statement between the scatterometer and the NIC ice charts, which is expected because of the high reliance by NIC on scatterometer data. While not used quantitatively as yet for sea ice mapping in the Antarctic, the images available are illustrative. In Fig. 6, we show a comparison between two AMSR-E images and the QuikSCAT images from the same two days. As shown here, the ice edge region is more clearly defined and slightly more extensive on scatterometer images in all regions than that seen on the AMSR-E passive microwave. The scatterometer-derived ice edge is similar to that seen on the NIC charts. In the interior pack ice, where ice concentration is higher, less distinction is seen between the two types of imagery. The snow cover and rough edges of the floes provide very high backscatter because of the effectively reflected radar signal back from the surface. Because the surfaces are generally covered by wet snow or slush during the summer, however, the brightness temperature as observed by AMSR-E is generally low (Fig. 6) making the sea ice less distinct from open water on passive microwave imagery. While scatterometer data have been only available over the past few years, comparing passive microwave and scatterometer data for that overlap period may still provide a better estimate of ice extent area, a correction that could be extended to earlier periods when only passive microwave is available. 


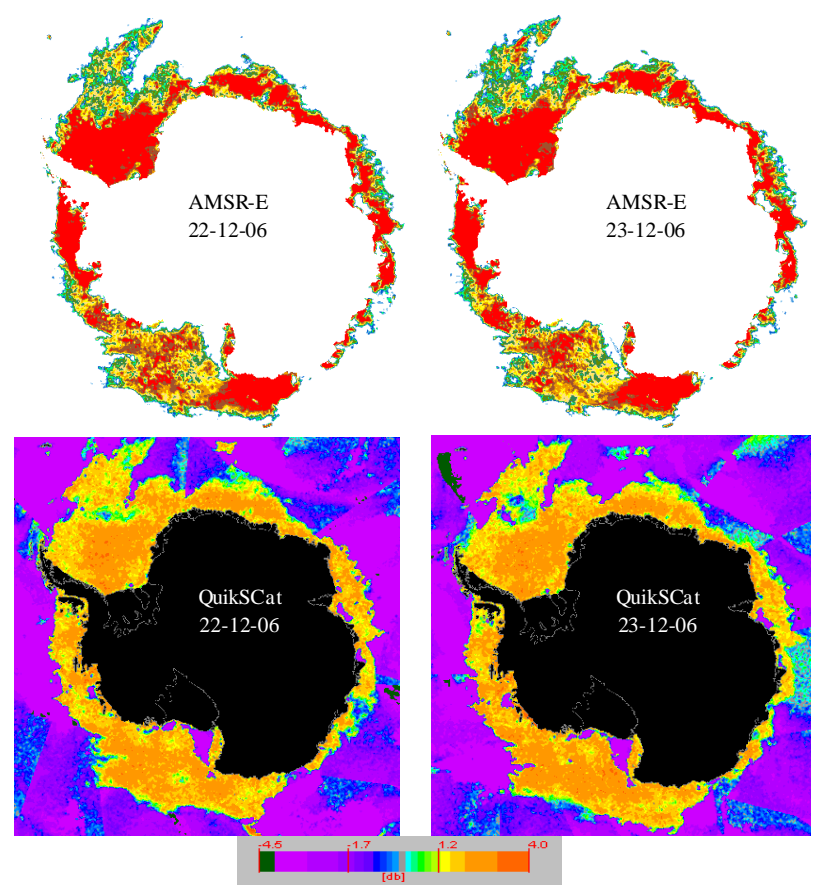

Fig. 6. Sea ice concentration for Antarctica from AMSR-E and QuikSCAT for two days period. Legend shows the variation of QuikSCAT signal strength (positive values, green-yellow-orange and above, indicate sea ice). Legend for AMSR-E is the same as in Fig. 5. QuikSCAT images downloaded from http://www.scp.byu. edu/data/Quikscat/Ice/Quikscat_ice.html

\section{Discussion}

Figure 5 shows the problematic nature of using AMSR-E to define the summer ice edge for Antarctic sea ice, particularly when compared to the higher resolution available from ships and NIC ice charts. If a 15\% "cutoff" is applied to the concentration contour for defining the ice edge, the comparison shows that many values of ice concentration up to $50 \%$ were missed in the AMSR-E comparison. Two factors can possibly contribute here, one that high concentration "bands" separated by large areas of open water in the ice edge zone are observed from ships or by higher resolution satellite imagery used for NIC charts. However, the spatial averaging, even of the higher resolution AMSR-E imagery $(12.5 \mathrm{~km} \times 12.5 \mathrm{~km}$ compared to $34 \mathrm{~km} \times 34 \mathrm{~km}$ from SSM/I) along with the wetter surfaces in the ice edge zone, suggests that, if these band features account for less than $15 \%$ of the pixel area $\left(156 \mathrm{~km}^{2}\right)$, they would not be used to define the ice edge. This cutoff percentage may also increase from the second factor, if the presence of flooded or wet surfaces further lessens the contrast between ice and open water and serves to drops concentration estimates below the cutoff. For ice concentration, Table 2 indicates on average, AMSRE overestimates the net ice concentration along the ship track even when the low values at the ice edge are considered as zero values. Analysis of the time-lapse video taken during the Oden cruise suggests one explanation for this. In the video, the ship could be seen taking turns to avoid areas of higher concentration, rather than a straight line track, that would have randomly sampled the area. As the leads can be wide ( $>200 \mathrm{~m}$ on average for ice concentrations less than about $80 \%$ ) the ship selection of the widest open water areas could further bias the concentration estimates to lower values in the $1 \mathrm{~km}$ radius circle used for a single ship observation, compared to the large-scale averaging of a satellite pixel $(12.5 \mathrm{~km} \times 12.5 \mathrm{~km})$. Worby et al. (2008) have suggested that ship avoidance of higher concentrations may be a factor in these satellite to ship comparisons in the interior pack ice. Knuth and Ackley (2006) found for example, in comparing satellite passive microwave estimates to helicopter digital imagery, that the satellite imagery consistently underestimated ice concentration for high concentrations rather than the overestimate implied here for ship observations only. Since the helicopter data was derived from straight line tracks with no bias for ice navigation in lower concentration, unlike the Oden ship track, this airborne comparison is probably more accurate for ice concentration. Concentration underestimates by AMSR-E mostly coincides with the regions of the sea ice edge where, usually, ice conditions are highly variable. Even though AMSR-E provides a continuous record of sea ice extent, ship observations clearly have shown seasonal effects on the estimation of the sea ice edge. As Worby and Comiso (2004) have reported for the ice growth (winter) season, previous passive microwave satellite data for sea ice edge agree well with ship observations. However, during the melting season, there was poor agreement probably due to the saturated ice at the edge and the presence of lower ice concentrations, as confirmed also for AMSR-E data in the present study. Comiso and Nishio (2008), have used adjustments of $25 \mathrm{~km}, 12.5 \mathrm{~km}$ and $6.25 \mathrm{~km}$ to determine effects on long term trends in sea ice extent from passive microwave imagery. While the Mode values shown in Table 2 are generally consistent with these values, the Mean values can be much larger, emphasizing that large areas of lower concentration ice can be missed by passive microwave analysis, particularly in summer conditions, in defining the area bounded by the ice extent. The values shown in Table 5 indicate area bounded by the ice edge from NIC values compared to the AMSR-E values are greater by $\sim 200$ to 400 thousand $\mathrm{km}^{2}$. The ice edge shown in the scatterometer depiction (Fig. 6) is in general agreement with that derived from NIC charts. Since the sector is 100 degrees longitude wide, the ice edge at this time of year around Antarctica (inset in Fig. 2) suggests overall that if this error applies on a circumpolar basis (360 degrees), the total area underestimate is 3.6 times the values in Table 5 , or between 0.7 and 1.5 million $\mathrm{km}^{2}$, underestimate of ice extent area by passive microwave compared to using NIC ice charts. 


\section{Conclusions}

In situ sea ice data taken from the 2006 cruise aboard the Oden were compared with satellite data from the same period. Good agreement was found between ship observations of ice edge position compared to NIC ice charts derived from high resolution satellite imagery. Passive microwave imagery alone, however, provided less agreement with ship observations and, therefore, NIC ice charts, with a strong bias toward underestimating the area bounded by the ice edge using passive microwave. The northward extent of the ice edge at the time of observation (NIC) had mean values varying from $38 \mathrm{~km}$ to $102 \mathrm{~km}$ on different days for the area as a whole as compared with the AMSR-E sea ice extent. We infer the passive microwave imagery has this resolution bias due to the low emissivities typical of wet snow covers and surface flooding, as well as low spatial resolution of small ice bands and low concentrations of dispersed small floes in the ice edge region. In areas of higher concentration in the interior pack, however, there is an indication that ship track bias to travel preferentially in the open water areas, as well the under sampling of a pixel $\left(156 \mathrm{~km}^{2}\right)$ by a single ship observation $\left(1-3 \mathrm{~km}^{2}\right)$ in highly variable summer conditions contributes to ship data under predicting ice concentration over the wider region. The result is a generally low overall correlation $\left(R^{2}=0.41\right)$ between ship estimates of ice concentration and passive microwave derived values. Given the good agreement between ice charts and ship observations for ice edge, an interesting future comparison would be between interior ice concentrations derived from ice charts or other satellite sensors (scatterometer, active radar, and visible imagery) compared to passive microwave values. While ship observations provide good agreement of the sea ice edge with the NIC ice charts, the differences between ice chart estimated areas and that estimated from passive microwave can be up to $14 \%$, or as large as 1.5 million $\mathrm{km}^{2}$ of circumpolar area greater than that determined from passive microwave on this date. Our conclusion is that considerable care is required in deriving the Antarctic sea ice extent, particularly estimates relying on passive microwave alone. Since the standard climatology of sea ice coverage over the past 30 years uses the passive microwave data, if this data set is relied on heavily for modeling intercomparisons, some caution may be necessary in using this record as the best indicator of model performance. We recommend that with the available records from scatterometer and active radar data that are approaching ten years, that a reanalysis of the Antarctic sea ice extent, compared to the passive microwave record over the same period, may be a prudent approach to verifying, and perhaps correcting that climatology.

Acknowledgements. We wish to acknowledge United States National Science Foundation (NSF) Grant ANT 0703682 for allowing us to participate in the Oden 2006 cruise, one of the first International Polar Year (IPY) activities. We are grateful to the National Snow and Ice Data Center in Boulder, Colorado for providing us AMSR-E images, and National Ice Center for providing ice chart data. We are also grateful to RPSC and Oden Crews for their assistance during the Oden 2006 cruise. We thank Anthony P. Worby and Edward Hanna for the review and editorial comments which improved the manuscript.

Edited by: E. Hanna

\section{References}

Ackley, S. F., Wadhams, P., Comiso, J. C., Worby, A. P.: Decadal decrease of Antarctic sea ice extent inferred from whaling records revisited on the basis of historical and modern sea ice records, Polar Res., 22(1), 19-25, ISSN:0800-0395, 2003.

Cavalieri, D., Parkinson, C., Gloerson, P., and Zwally, H. J.: Sea ice concentrations from Nimbus-7 SMMR and DMSP SSM/I passive microwave data, June to September 2001, Boulder, CO, USA, National Snow and Ice Data Center, Digital media and CDROM, updated 2005, 1997.

Cavalieri, D. and Comiso, J.: AMSR-E/Aqua Daily L3 $12.5 \mathrm{~km} \mathrm{~Tb}$, Sea Ice Conc., and Snow Depth Polar Grids V001, March to June 2004, Boulder CO, USA, National Snow and Ice Data Center, Digital media, updated daily, 2004.

Cavalieri, D. and Parkinson, C. L.: Antarctic sea ice variability and trends, 1979-2006, J. Geophys. Res., 113, C07004, doi:10.1029/2007JC004564, 2008.

Comiso, J. C. and Nishio, F.: Trends in the sea ice cover using enhanced and compatible AMSR-E, SSM/I and SMMR data, J. Geophys. Res., 113, C02S07, doi:1029/2007JC004257, 2008.

Comiso, J. C., Cavalieri, D. J., and Markus, T.: Sea ice concentration, ice temperature and snow depth using AMSR-E data, IEEE T. Geosci. Remote, 41, 243-252, 2003.

De la Mare, W. K.: Abrupt mid-twentieth-century decline in Antarctic sea ice extent from whaling records, Nature, 389, 5760, 1997.

Godin, R. H. and Raymond, H.: Sea ice charts of the Navy/NOAA Joint Ice Center, Glaciological Data, Report GD-Il "Snow Watch 1980", 1981.

Hunke, E. and Ackley, S.: A numerical investigation of the 19971998 Ronne Polynya, J. Geophys. Res., 106(C10), 2237322382, 2001.

Knuth, M. F. and Ackley, S. F.: Summer and early-fall sea-ice concentration in the Ross Sea: comparison of in situ ASPeCt observations and satellite passive microwave estimates, Ann. Glaciol., 44, 303-309, 2006.

Markus, T. and Cavalieri, D. J.: An enhancement of the NASA Team sea ice algorithm, IEEE T. Geosci Remote, 38, 1387-1398, 2000.

Nghiem, S. V., Van Woert, M. L., Neumann, G.: Rapid formation of a sea ice barrier east of Svalbard, J. Geophys. Res., 110, C11013, doi:10.1029/2004JC002654, 2005.

Nihashi, S. and Cavalieri, D.: Observational evidence of a hemispheric-wide ice-ocean albedo feedback effect on Antarctic sea ice decay, J. Geophys. Res., 111, C12001, doi:10.1029/2005JC003447, 2006.

Nihashi, S. and Ohshima, K. I.: Relationship between the sea ice decay and solar heating through open water in the Antarctic sea ice zone, J. Geophys. Res., 106(16), 16767-16782, 2001. 
Parkinson, C. L.: Trends in the length of the Southern Ocean sea-ice season, 1979-1999, Ann. Glaciol., 34(1), 435-440, 2002.

Worby, A. P. and Comiso, J. C.: Studies of the Antarctic sea ice edge and sea ice extent from satellite and ship observations, Remote Sens. Environ., 92, 98-111, doi:10.1016/j.rse.2004.05.007, 2004.
Worby, A. P. and Allison, I.: A ship-based technique for observing Antarctic sea ice: Part I Observational Techniques and Results, Antarctic CRC Research Report, 14, 63 pp., 1999.

Worby, A., Geiger, C. A., Paget, M. J., Van Woert, M. L., Ackley, S. F., and DeLiberty, T. L.: The thickness distribution of Antarctic sea ice, J. Geophys. Res., 113, C05S92, doi:10.1029/2007JC004254, 2008. 